\title{
O LÚDICO E AS RELAÇÕES AFETIVAS: TRABALHANDO A AGRESSIVIDADE NA ESCOLA
}

\author{
Daniela Ribeiro Braga, Andréia Cristiane Silva Wiezzel \\ Universidade Estadual Paulista - FCT/UNESP. Curso de Pedagogia, Presidente Prudente - SP. E-mail: daniela- \\ ribeiro@outlook.com
}

\section{RESUMO}

A pesquisa ora apresentada foi desenvolvida em uma escola de Educação Infantil da Rede Municipal de Presidente Prudente-SP e trabalhou com um aluno, tido por sua professora, como agressivo, visando favorecer seu desenvolvimento emocional, de forma que suas interações sociais pudessem ser mais satisfatórias. A pesquisa teve como referencial a concepção que a psicanálise winnicottiana nos traz a respeito do tema agressividade. Nesta pesquisa qualitativa, de tipo estudo de caso, utilizou-se, como instrumentos de coleta de dados, observações, entrevistas com pais e professora e atividades lúdicas com a criança. A estagiária levou o aluno participante à brinquedoteca escolar por cerca de cinquenta minutos semanais durante o ano letivo de 2013. Passados cerca de dois meses a professora e a estagiária começaram a perceber mudanças na conduta da criança, evidenciando atitudes mais construtivas.

Palavras-chave: lúdico; relações afetivas; agressividade; criança; escola.

\section{THE LUDIC AND AFFECTIVE RELATIONS: A WORKING AGGRESSION IN SCHOOL}

\begin{abstract}
The research presented here was developed in a school for Early Childhood Education of Presidente Prudente-SP Municipal Network and worked with a student, had by his teacher as aggressive in order to facilitate their emotional development, so that their social interactions could be more satisfactory. The research had as a reference design that Winnicott's psychoanalysis brings about the theme aggressiveness. In this qualitative research, a case study, we used as instruments for data collection, observations, interviews with parents and teacher and playful activities with your child. The trainee took the participant to the playroom school student for about fifty minutes per week during the school year of 2013 After about two months the teacher and the intern began to notice changes in the behavior of children, showing more constructive attitudes.
\end{abstract}

Keywords: playful; affective relationships; aggressiveness; child; school. 


\section{INTRODUÇÃO}

No ano de 2009 iniciou-se o projeto Contribuições às relações interpessoais e a dinâmica em sala de aula na FTC - Unesp, Campus de Presidente Prudente, com o objetivo de realizar um trabalho em extensão e pesquisa que pudesse transformar as relações interpessoais no âmbito escolar. O projeto surgiu a partir de constantes relatos de professores, principalmente em relação a manifestações agressivas apresentadas por alguns alunos em sala de aula, deixando-os professores preocupados quanto ao desenvolvimento da socialização.

Pode-se compreender que a agressividade inicia-se no começo da vida, tendo como exemplo o "chute" ainda na barriga da mãe, enquanto o bebê está sendo gerado. 0 objetivo desta ação é que o bebê descubra o que é "eu" e o que não é, sendo, também, uma forma de reconhecimento do espaço.

A agressividade se manifesta antes mesmo do nascer do bebê e estará presente ao longo de toda sua vida. As condições do meio social influenciam muito em como pode ser manifestada, por isso a mãe ou cuidador precisa buscar meios de atendimento às necessidades afetivas das crianças, passando segurança a elas, para que possam ter confiança no mundo.

Assim que a criança nasce, precisa de uma mãe suficientemente boa, sendo esta aquela que se adapta às necessidades do bebê e as atenda. Nespe processo a criança ganha confiança no mundo, entendendo que uma experiência está ligada a outra. $O$ atendimento às necessidades afetivas é tão importante para a criança quanto a higiene e alimentação, pois a relação afetiva contribui positivamente à construção das bases do desenvolvimento emocional do indivíduo.

As crianças agressivas testam os pais, desafiam, provocam e com isso estão sinalizando que precisam de auxílio para lidar com esta agressividade. Quando a agressividade não é contida no espaço familiar, as crianças vão buscar na escola essa contenção, forçando o ambiente a ser um espaço em que se sintam seguras. As crianças que têm a segurança em casa, vão à escola mais em busca do intelectual, cognitivo. Os pais, portanto, quando mantém as crianças com a assistência necessária de amor e carinho, influenciarão positivamente no desenvolvimento emocional da criança.

Diante do ato agressivo os pais ou professores devem conter a criança, exercendo uma função de autoridade, sem desconsiderar o apoio afetivo.

É tarefa de pais e professores cuidar para que as crianças nunca se vejam diante de uma autoridade tão fraca a ponto de ficarem livres de qualquer controle ou, por medo, assumirem, elas próprias autoridades. A assunção de autoridade provocada por ansiedade significa ditadura, e aqueles que tiverem a experiência de deixar as crianças controlarem seus próprios destinos sabem que o adulto 
tranquilo é menos cruel, enquanto autoridade, do que uma criança poderá se tornar se for sobrecarregada com responsabilidades. (WINNICOTT, 1982, p. 101)

A autoridade dos pais, nesse sentido, é fundamental para o crescimento da criança, minimizando as complicações que a agressividade mal resolvida pode trazer. Todo o processo inicia-se com o amor materno e, mesmo que os professores se empenhem, nunca e nem devem substituir os pais.

Por isso, o amor materno que uma criança necessita é tão facilmente encontrado no seio da família e extremamente dificil fora dela. Os serviços habitualmente prestados pelos pais a seus filhos são de tal maneira considerados naturais que sua grandiosidade é esquecida. (BOWLBY, 2006, p. 70)

Por isso a importância de professores na educação infantil investirem no aspecto afetivo, proporcionando um ganho significativo para o aluno em sua saúde mental. A criança busca no professor o afeto e a assistência para que possa contolar sua agressividade.

Os cursos de formação de professores ainda não contemplam o estudo da agressividade na primeira infância, o que dificulta a interação dos professores com os alunos que a manifestam em sala de aula. Desta forma o projeto contribuiu à formação acadêmica por meio da relação teoria-prática, tendo em vista que, com a proximidade com o ambiente escolar é possível construir uma linha de pensamento maior no que se refere ao desenvolvimento emocional e às necessidades afetivas infantis, além de trazer experiência com as crianças agressivas e tímidas.

Será apresentado neste artigo o resultado do projeto realizado com uma criança de uma Escola Municipal de Presidente Prudente-SP, abordando o trabalho de uma das alunas voluntárias. $\mathrm{O}$ artigo se refere, portanto, a um recorte do projeto mais amplo.

O objetivo principal do projeto, neste caso específico, foi o de amenizar os quadros de agressividade excessivos da criança participante, tomando-se, como base, o brincar.

\section{METODOLOGIA}

O projeto foi submetido ao Comitê de Ética em Pesquisa da Faculdade de Ciências e Tecnologia - Unesp - Presidente Prudente, sendo aprovado (processo 66/2009). A pesquisa de natureza qualitativa, foi desenvolvida com um garoto de quatro anos - Rick (nome fictício) - aluno do Pré I, que estudava em período integral em uma escola de Educação Infantil de Presidente Prudente-SP. Foi indicado ao projeto devido apresentar atitudes agressivas em sala de aula, na percepção da professora. 
Os instrumentos de coleta de dados foram: observação da criança em sala de aula, entrevista com o pai e, posteriormente, com a professora (momentos em que assinaram aos Termos de Consentimento Livre e Esclarecido) e atividades lúdicas com a criança. Os dados obtidos foram categorizados e analisados com base na teoria winnicottianna.

Os encontros lúdicos, com a criança, ocorreram todas as terças-feiras, no período da manhã, tendo duração de 50 minutos. Rick participou do projeto, com idas à brinquedoteca, no período de $6 / 08 / 2013$ até $26 / 11 / 2013$, com o total de 14 encontros. Nestes encontros lúdicos com a estagiária, Rick tinha toda libertadade de escolher os brinquedos e brincadeiras. Também tinha a opção de inserir a estágiária nas brincadeiras, caso contrário, esta apenas observava o seu brincar.

O brincar foi escolhido como forma de coleta de dados e intervenção pois, para Winnicott (1982) as crianças brincam para dominar angústias, devaneios e ideias, o brincar é o ponto de encontro do mundo interno com o externo, a realidade e a fantasia, o mundo infantil e adulto. Por meio do brincar a criança pode realizar desejos, lidar com situações difíceis e até mesmo elaborálas.

\section{RESULTADOS}

\section{Caracterização da criança}

Conforme a entrevista fornecida pelo pai, Rick tem um histórico conturbado desde a gestação. A mãe, sendo hipertensa, teve uma complicação e Rick nasceu, prematuramente, aos sete meses, precisando ficar no hospital por cerca de 15 dias. Depois de sair do hospital, foi cuidado pela avó paterna por volta de duas semanas e, após esse período, passou a ser cuidado em uma creche. Nos seis primeiros meses do nascimento necessitava de muito cuidado, pois teve começo de refluxo.

A família, durante a semana, quase não tinha contato com o filho, tendo somente um certo espaço à noite, porém, o ambiente envolvia desentendimentos e vícios, tendo a criança presenciado situações complicadas. Os pais trabalhavam em tempo integral e, até mesmo nas férias, o mantinham em outras instituições que prestavam serviços durante este período. Rick não tem irmãos, a mãe decidiu não ter mais filhos por possuir problemas de hipertensão.

O pai destacou ainda que o filho apresentava atos agressivos verbais em casa e que estes tiveram início no começo de 2013, quando Rick mudou de escola e se iniciaram desentendimentos entre o casal. Afirmou que Rick era "agitado", gostava de brincar, mas era mal humorado de 
manhã, pois queria dormir. O garoto era um pouco obeso e o pai disse que ele era ansioso e gostava de comer. O pai, por sua vez, disse ser "chato", "nervoso" e que "gostava muito de festas".

A professora, em sua entrevista, destacou o comportamento do garoto em sala de aula como sendo reservado, com poucos amigos, com dificuldade na socialização, era agressivo fisicamente e, por isso, as outras crianças evitavam contato com ele. Devido a tantas confusões, Rick passou a ser taxado pelos próprios alunos de sua sala como o responsável por todas as dificuldades que surgissem, mesmo que não estivesse participando da situação. A professora apontou que o pouco acompanhamento da familia no educar e a falta de trabalhar o aspecto afetivo, podem ser possíveis causas da agressividade.

\section{DISCUSSÃO}

\section{Os encontros lúdicos}

Os encontros lúdicos, inicialmente, foram marcados por brincadeiras que envolviam carrinhos, bonecos, super-herói, martelo e acessórios da maleta de médico. Rick parecia tentar consertar algo e, para isso, martelava vários dos brinquedos disponíveis na brinquedoteca, fazia "fórmulas" - como se fossem remédios - e oferecia a estagiária para que tomasse, ressaltando que ela "ficaria melhor". Alternava essas brincadeiras com outras nas quais atropelava um personagem denominado por ele como "caçador" ou provocava batidas entre dois carrinhos.

Houve um pouco de dificuldade na interação com o aluno no início, pois ele parecia desconfiado, receoso e isto ocorreu desde o período de observação em sala de aula. Enquanto brincava, ele oferecia outros brinquedos à estagiária, para que ela brincasse sozinha. Após o terceiro encontro foi possível observar que uma relação empática e de confiança estava se estabelecendo. Começou a construir estradas e fazer com que os carrinhos passassem por ela, às vezes "consertava" trechos de tal estrada. No quarto encontro lúdico o aluno já ia receber a estagiária no portão da escola.

A partir disso passou a brincar com o boneco "Batman" dizendo que estava triste, pegava o martelo e martelava os brinquedos da sala. Depois pegou uma chave de fenda e uma serra e tentava "consertar" um carrinho que estava quebrado. Tentou "consertar" e levar o carrinho, escondido no bolso, para casa. Faltou uma semana à escola e, ao retornar, as brincadeiras foram explicitando melhor os conflitos de Rick.

Passou a se interessar por quebra-cabeça e, durante a montagem, pediu auxílio à estagiária bem como relatou sobre um dia em que encontrou sua mãe caída no chão (desmaiada) e que havia vários copos quebrados ao seu redor. Ele disse ainda, que o pai dele jogou água sobre 
ela e chamou o médico. O garoto estava muito impressionado, pois pensou que a mãe havia morrido. Na verdade a mãe dele tem problemas com bebida alcoólica, algo revelado pelo pai na entrevista. O suposto motivo seria ciúme.

Nos encontros seguintes relatava pesadelos nos quais a mãe estava em perigo, em meio a muitos monstros e o "Homem Aranha" estava presente. Alternava os relatos com brincadeiras com os bonecos de super-herói.

Ao final dos encontros, começou a brincar de "mágico", fazendo com que os brinquedos que usualmente utilizava, aparecessem e desaparecessem. Começou a brincar de encaixar e empilhar copinhos, escondia as peças, brincava de adivinhar as cores. Nesse momento a professora começou a relatar que o aluno estava mais tranquilo em sala de aula, se envolvendo menos em agressões físicas, passando a ouvir mais e participar das aulas, ajudando a organizar a sala e apagar a lousa.

Nos últimos encontros ele brincou de médico e fazia "fórmulas", porém, ao invés de "aplicá-las" na estagiária, como sempre fazia, aplicou em si mesmo, dizendo que o seu coração ficaria forte, apesar da dor. Posteriormente fez um "curativo" no braço, com capa do Batman.

\section{CONCLUSÃO}

A partir do trabalho realizado pode-se verificar alguns aspectos que possivelmente colaboraram nas dificuldades que Rick apresentava nos relacionamentos em sala de aula. A começar pelo nascimento prematuro e exposição a várias instituições e pessoas cuidando dele por períodos curtos, ocorrendo muitas interrupções nas relações afetivas. Necessitava muito da presença da mãe, mas, por motivos de saúde, isto não foi possível. Houve uma mudança de escola e dificuldades nas relações conjugais, em que o próprio pai as associou com o início das manifestações agressivas da criança em casa. Além disso, há a questão da rejeição que Rick sente em sala de aula, ao ser culpabilizado por todos os problemas que ocorrem, mesmo que ele não esteja necessariamente envolvido.

Também conclui-se que $o$ ato de brincar contribui positivamente para o desenvolvimento emocional infantil. Como o brincar tem como função expressar o mundo interno da criança, servindo para dominar angústias, expandir a socialização, ter prazer e estimular a imaginação, Rick teve um espaço em que pode fazer uso de todas essas propriedades do brincar e reorganizar suas experiências difíceis. 
As mudanças nas condutas agressivas de Rick foram progressivas, apresentando diferenças, inclusive, nas atividades lúdicas, que deixaram de ser utilizadas apenas como meio para expressão da agressividade mas como forma de lidar com os conflitos e construir o seu futuro.

\section{REFERÊNCIAS}

BOWLBY, J.D. Cuidados maternos e saúde mental. Vera Lúcia Baptista De Souza (trad.). São Paulo: Martins Fontes, 2006.

WINNICOTT, D.W. A criança e seu mundo. Álvaro Cabral (trad.). Rio de Janeiro: LTC, 1982. 